examination and by chart review were correlated to the presence or not of aPL TP.

Results: Nineteen out of 74 pAPS patients had aPL TP (25.7\%). Demographic and clinical characteristics are shown in Table 1. In a bivariate analysis, TP was associated with the presence of combined thrombotic and obstetric manifestations $(p=0.008)$, three or more abortions (abortion $3+; p=0.043)$, and livedo $(p=0.023)$. In a multivariate regression analysis, the model was adjusted to age, sex, race and variables with $\mathrm{p}<0.10$ in the bivariate analysis (arterial thrombosis, abortion $3+$, livedo, thrombocytopenia, and thrombotic+obstetric). After the analysis, arterial thrombosis (OR 5.74; Cl95\% 1.31-25.05; $\mathrm{p}=0.02$ ) and abortion 3+ (OR 12.55; CI95\% 1.01-156.54; $p=0.049$ ) were associated with TP.

Conclusions: In our cohort of primary APS patients, triple positivity was associated with arterial thromboses and the occurrence of 3 or more abortions, with increased risk over 5 and 12 folds, respectively.

Disclosure of Interest: None declared

DOI: 10.1136/annrheumdis-2017-eular.6774

\section{THU0254 COMPARISON OF URBAN VERSUS RURAL ENVIRONMENT ASSOCIATED SYSTEMIC LUPUS ERYTHEMATOSUS (SLE): RISK AND CLINICAL FEATURES}

I. Gergianaki ${ }^{1,2}$, A. Fanouriakis ${ }^{3}$, C. Adamichou ${ }^{2}$, G. Spyrou ${ }^{4}$, P. Sidiropoulos ${ }^{2}$, D. Boumpas ${ }^{1,3,5,6,7}$, G. Bertsias ${ }^{1,1,2,2}$. ${ }^{1}$ Laboratory of Autoimmunity and Inflammation, Institute of Molecular Biology-Biotechnology, FORTH;

${ }^{2}$ Rheumatology, Clinical Immunology and Allergy, University of Crete School of Medicine, Iraklio; ${ }^{3} 4$ th Department of Medicine, Attikon University Hospital, National and Kapodistrian University of Athens Medical School, Athens;

${ }^{4}$ Laboratory of Autoimmunity and Inflammation, University of Crete School of Medicine, Iraklio; ${ }^{5}$ Laboratory of Autoimmunity and Inflammation, Biomedical Research Foundation of the Academy of Athens, Athens, Greece; ${ }^{6}$ Medical School, University of Cyprus, Nicosia, Cyprus; ${ }^{7}$ Joint Rheumatology Program, Attikon University Hospital, National and Kapodistrian University of Athens Medical School, Athens, Greece

Background: SLE originates from the complex interplay between genetic, epigenetic and environmental factors but the effects of the latter remain elusive. Very few studies have examined the impact of the place of residence (urban/rural) on SLE clinical profile and outcomes.

Objectives: To evaluate the effect of rural versus urban place of residency with regards to: i) SLE occurrence; ii) delay in diagnosis; iii) clinical manifestations, severity and non-reversible organ damage; iv) comorbidities and hospitalizations. Methods: We employed data from the Lupus Epidemiology \& Surveillance project in Crete (750 adult SLE patients with $\geq 4$ ACR-1997 classification criteria). Crete is a Mediterranean island with genetically stable and homogenous population in ethnicity and sociodemographic characteristics, with no significant inequalities regarding access to healthcare facilities; $61 \%$ of the inhabitants live in rural ( $<10,000$ people) and $47 \%$ in urban areas ( $>10,000$ people). Demographics and residency history were retrieved from face interviews. In 200 patients with exclusively urban or rural residence, a subanalysis was performed in relation to disease risk, diagnosis age, disease severity, renal and neuropsychiatric involvement, and organ damage (SLICC damage Index [SDI]).

Results: SLE prevalence (December 2013) varied across the four geographical prefectures of Crete (Figure 1) and was significantly higher in urban (165/10 $)$ than rural $\left(123 / 10^{5}\right)$ areas $(p<0.001)$. The relative risk of SLE in urban versus rural regions was 2.0 (95\% Confidence Interval 1.5-2.9). Notably, patients in urban regions had lower age of diagnosis (38.0 \pm 13.4 vs. $44.5 \pm 14.8$ years, $\mathrm{p}=0.005)$ and female-to-male ratio $(6.5: 1 \mathrm{vs} .11: 1)$ than those in rural regions. Delay $>2$ years between symptoms onset and SLE diagnosis occurred in $42 \%$ of patients from rural areas as compared to $32 \%$ of those from urban areas $(p=0.01)$. Acute cutaneous lupus was more prevalent in the rural environment (83.9\% vs. $72.6 \%, p=0.05)$ whereas the opposite trend was noted for discoid rash $(2.3 \%$ vs. $16.8 \%, p=0.001)$. Nephritis occurred less frequently $(10.3 \%$ vs. $12.4 \%)$ and neuropsychiatric disease was more prevalent $(14.9 \%$ vs. $10.6 \%)$ in rural than urban patients albeit non-significantly. Prevalence of mild, moderate, and severe disease was $42 \%, 40 \%$, and $18 \%$ in patients from rural areas, the respective figures being $55 \%, 28 \%$ and $18 \%$ in those from urban areas $(p=0.12)$. Hospitalization due to active lupus did not differ between the two groups. At last follow-up, $45.3 \%$ of the patients living in urban and $51.9 \%$ of patients in rural areas had no organ damage $(p=0.89)$. Concurrent allergic diseases were more frequent in urban patients $(30.9 \%$ vs. $14.3 \%, p=0.045)$, particularly allergic rhinitis (8.8\% vs. $2.3 \%, p=0.05)$.

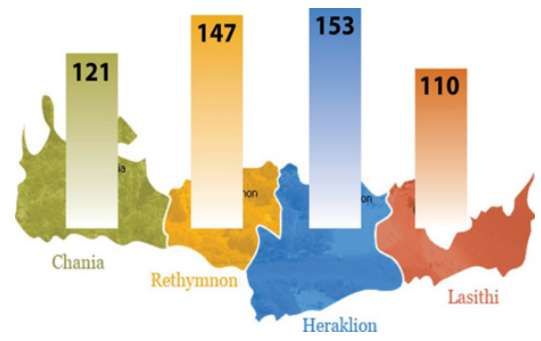

Conclusions: SLE may be more prevalent in urban than rural regions and urbanization is associated with increased risk of SLE and earlier age of disease onset.

Our results suggest an important effect of the environment on SLE occurrence and characteristics, which warrants further investigation.

Disclosure of Interest: None declared

DOI: 10.1136/annrheumdis-2017-eular.6779

\section{THU0255 COMPARISON OF REMISSION AND LUPUS LOW ACTIVITY STATE AS PREDICTORS OF ORGAN DAMAGE}

M. Petri ${ }^{1}$, L.S. Magder ${ }^{2} .{ }^{1}$ Johns Hopkins University School of Medicine;

${ }^{2}$ University of Maryland, Baltimore, United States

Background: Outcome measures that combine control of SLE activity and prednisone reduction are clinically relevant. A clinical goal in SLE is to reduce risk of long-term organ damage.

Objectives: We assessed whether two recently proposed disease activity outcomes were predictive of future damage.

Methods: For each month of follow-up in a large SLE cohort, we determined whether the patient was in Clinical Remission (as defined by the DORIS work group) or low lupus disease activity state (LLDAS) (as defined by Franklyn et al.). Clinical Remission was defined as a $P G A<0.5$, clinical $S L E D A I=0$ and no prednisone or immunosuppressants. Clinical Remission on Treatment allowed for prednisone $\leq 5 \mathrm{mg} /$ day and immunosuppressant use. LLDAS was defined as a $\operatorname{SLEDAI} \leq 4, \mathrm{PGA} \leq 1.0$, no major organ activity, and no new activity. LLDAS on treatment allowed for prednisone use $<7.5 \mathrm{mg} / \mathrm{d}$ and immunosuppressants. Damage was defined using the SLICC/ACR index.

Results: There were 81,118 person-months observed among 2,026 patients (92\% female, $53 \%$ Caucasian, 39\% African-American). Table 1 shows the rates of damage, per person month, in subgroups defined by Remission or LLDAS.

Table 1. Rates of new damage, in subgroups defined by past levels of disease activity

\begin{tabular}{|c|c|c|c|c|c|}
\hline $\begin{array}{l}\text { Percentage of } \\
\text { prior months in: }\end{array}$ & $\begin{array}{l}\text { Number of } \\
\text { person-months } \\
\text { observed }\end{array}$ & $\begin{array}{l}\text { Number of } \\
\text { months with } \\
\text { an increase in } \\
\text { SLICC/ACR } \\
\text { damage }\end{array}$ & $\begin{array}{c}\text { Rate of } \\
\text { damage per } \\
100 \text { person- } \\
\text { months }\end{array}$ & Rate ratios & P-values \\
\hline \multicolumn{6}{|l|}{ Clinical Remission } \\
\hline None & 35,772 & 406 & 1.13 & 1.0 (Ref) & \\
\hline Not none, but $<25 \%$ & $\% \quad 14,358$ & 102 & 0.71 & $0.60(0.48,0.75)$ & $<0.0001$ \\
\hline $25 \%$ to $50 \%$ & 6573 & 50 & 0.76 & $0.66(0.46,0.94)$ & 0.023 \\
\hline $50 \%$ to $75 \%$ & 3845 & 27 & 0.70 & $0.63(0.42,0.97)$ & 0.035 \\
\hline $75 \%+$ & 1,641 & 10 & 0.61 & $0.58(0.30,1.15)$ & 0.12 \\
\hline \multicolumn{6}{|c|}{ Clinical Remission on Treatment } \\
\hline None & 16,491 & 250 & 1.52 & 1.0 (Ref) & \\
\hline Not none, but $<25 \%$ & $\% \quad 20,169$ & 170 & 0.84 & $0.54(0.44,0.67)$ & $<0.0001$ \\
\hline $25 \%$ to $50 \%$ & 14,344 & 103 & 0.72 & $0.46(0.36,0.60)$ & $<0.0001$ \\
\hline $50 \%$ to $75 \%$ & 8396 & 54 & 0.64 & $0.43(0.30,0.60)$ & $<0.0001$ \\
\hline $75 \%+$ & 2,789 & 18 & 0.65 & $0.45(0.27,0.75)$ & 0.0019 \\
\hline \multicolumn{6}{|l|}{ LLDAS } \\
\hline None & 30,366 & 343 & 1.13 & 1.0 (Ref) & \\
\hline Not none, but $<25 \%$ & $\% \quad 10,880$ & 106 & 0.97 & $0.86(0.69,1.07)$ & 0.18 \\
\hline $25 \%$ to $50 \%$ & 5012 & 40 & 0.80 & $0.70(0.51,0.98)$ & 0.037 \\
\hline $50 \%$ to $75 \%$ & 8494 & 60 & 0.71 & $0.63(0.48,0.83)$ & \\
\hline $75 \%+$ & 7,527 & 46 & 0.61 & $0.54(0.40,0.73)$ & $<0.0001$ \\
\hline \multicolumn{6}{|l|}{ LLDAS on Treatment } \\
\hline None & 7,656 & 117 & 1.53 & 1.0 (Ref) & \\
\hline Not none, but $<25 \%$ & $\% \quad 10,555$ & 134 & 1.27 & $0.83(0.65,1.06)$ & 0.14 \\
\hline $25 \%$ to $50 \%$ & 12,686 & 129 & 1.02 & $0.66(0.51,0.85)$ & 0.0013 \\
\hline $50 \%$ to $75 \%$ & 18,151 & 133 & 0.73 & $0.48(0.37,0.61)$ & 0.0010 \\
\hline $75 \%+$ & 13,141 & 82 & 0.62 & $0.40(0.30,0.54)$ & $<0.0001$ \\
\hline
\end{tabular}

Damage rates were relatively low when LLDA was achieved at least $50 \%$ of the time. These rates were similar to those experienced by patients who met a more stringent treatment restriction with Remission on Treatment at least $50 \%$ of the time.

Conclusions: The equivalence of LLDAS and DORIS remission on treatment is welcome news, as LLDAS on treatment $>50 \%$ of the time is an easier goal to achieve (3 times more person-months observed in our cohort) and more realistic as a clinical trial outcome.

Disclosure of Interest: None declared

DOI: 10.1136/annrheumdis-2017-eular.1646

\section{THU0256 DEVELOPMENT AND VALIDATION OF A SCORE TO PREDICT THE RISK OF SEVERE INFECTION IN SLE}

B. Tejera Segura ${ }^{1}$, I. Rúa-Figueroa ${ }^{2}$, J. Pego-Reigosa $^{3}$, V. del Campo Pérez ${ }^{3}$, D. Isenberg ${ }^{1}$, A. Rahman ${ }^{1} .{ }^{1}$ University College London Hospital, London, United Kingdom; ${ }^{2}$ Hospital Universitario Dr.Negrín, Las Palmas de Gran Canaria;

${ }^{3}$ Complejo Hospitalario Universitario de Vigo, Vigo, Spain

Background: Infection is a major cause of morbidity and mortality in SLE patients. It would be helpful to have a tool to predict the risk that an individual patient with SLE will develop serious infection.

Objectives: To develop a predictive risk calculator algorithm (SCORE) that 